\title{
Water Movement in Strawberry Beds ${ }^{1}$
}

\section{John R. Duval and Eric Simonne ${ }^{2}$ \\ Water Movement}

An increasing concern for proper water usage and irrigation efficiency requires a better understanding of water movement in strawberry beds. The major factor that determines water movement in the soil is macro- and micro-pore space in the soil. Pores in the soil are simply free space not occupied by soil particles, this can be visualized as air filled spaces between soil particles. While there is no definitive differentiation between macro- and micro-pores, macro-pores are generally considered to be larger than 0.06 millimeter in diameter and anything smaller is considered a micro-pore. Sandy soils usually have a porosity of $35-50 \%$ and finer textured soils have porosity of $40-60 \%$. With larger soil constituents sandy soils will have a greater number of macro pores. Water movement through macro-pores usually is accomplished from mass flow. This is the movement of water due to gravity, generally in a downward direction. In micro-pores water movement is more commonly a factor of capillary action, which can move water laterally. The distribution of macro- and micro-pores depends on several factors, soil compaction, aggregation, and type. Soil compaction and aggregation can be altered to some degree, while soil type is a location specific factor that can only be changed by changing location or the movement of mass quantities of soil.

\section{Soil Compaction}

Soil compaction may be the easiest factor to control in a field setting. The use of deep tillage, to breakup compacted layers in soil, can improve the drainage of a field. Because macro-pore volume of the compacted layer is increased, gravitational water is allowed to move freely through it instead of laterally on top of it. If this is true then the reverse should also be true, to improve the lateral movement of water in a planting bed, a more compacted bed will have fewer macro-pores and more micro-pores, due to the forcing of soil particles together, improving movement to the sides or shoulders of the bed. As an example, in a "loose" bed water from a drip tape will preferentially move downward, whereas in a "tight" bed water movement will still move downward, but not at as great a rate with more water being moved towards the side of the bed through capillary action of the micro-pores.

1. This is document HS-912, one of a series of the Horticultural Sciences Department, Gulf Coast Research and Education Center - Bradenton, Florida. Cooperative Extension Service, Institute of Food and Agricultural Sciences, University of Florida. Please visit the EDIS Web site at http://edis.ifas.ufl.edu.

2. John R. Duval, assistant professor, Horticultural Sciences Department, Gulf Coast Research and Education Center - Dover, Florida, and Eric Simone, assistant professor, Horticultural Sciences Department, Cooperative Extension Service, Institute of Food and Agricultural Sciences, University of Florida, Gainesville, FL 32611.

The Institute of Food and Agricultural Sciences is an equal opportunity/affirmative action employer authorized to provide research, educational information and other services only to individuals and institutions that function without regard to race, color, sex, age, handicap, or national origin. For information on obtaining other extension publications, contact your county Cooperative Extension Service office. Florida Cooperative Extension Service/Institute of Food and Agricultural Sciences/University of Florida/Christine Taylor Waddill, Dean. 


\section{Soil Aggregation}

Soil aggregation is the binding or flocculation of soil particles to one another. Soil aggregates are naturally occurring clumps of soil and help increase the numbers of micro-pores present in the soil. There are four factors that control soil aggregation, physical movements of soil particles, organic matter content of the soil, cation concentrations in the soil, and tillage. Organic matter in the soil is the major factor contributing to aggregate formation. As organic materials break down, bacteria and fungi produce gels and other products which bind soil particles together. Physical movement of soil particles can be accomplished through natural freeze - thaw and wetting - drying cycles, action of soil organism, and root growth. These actions force soil particles together promoting aggregation. Some cations (positively charged ions) such as calcium and magnesium (which both have a +2 charge) can help bind negatively charged soil particles together in a process called flocculation. However, cations such as sodium (which only has a +1 charge) can cause the dispersal of soil particles. Tillage can have both a positive and negative impact on soil aggregation. Incorporation of organic materials uniformly in the soil (from crop residues or green manure and cover crops) enhances soil aggregation in the short term. However, in the long term, repeated tillage operations speed up the break down of organic matter in the soil reducing aggregation and movement of machinery through the field can break stable soil aggregates.

\section{Trials}

What does this mean to a strawberry grower? If the physical properties of a soil are known and how that soil behaves, determinations can be made on the amount of water needed to irrigate to a certain depth or to wet a given volume of the bed. In the sandy soils surrounding Plant City, lateral movement of water in the soil is very poor. Drs. Joe Noling and James Gilreath have preformed tests using dyes to determine where water moves in terms of fumigant application. These tests were duplicated looking at the use of different drip tapes with different flow rates and emitter spacing and their effect on water movement. On a commercial farm, two tapes of 24 and 27 with flow rates of gal/100 ft/hour with 12 inch emitter spacing and at the GCREC-Dover a tape with 4 inch emitter spacing and a $32 \mathrm{gal} / 100 \mathrm{ft} /$ hour flow rate were tested. Both test areas contained living strawberry plants spaced 15 inches apart and had received no irrigation for a month. All beds in this study were "tight" beds, formed with 3 passes of bedding equipment. Treatments were irrigation lengths of 1,2, 3, 4, 6, and 8 hours. During the first 20 minutes of irrigation of all beds, a blue indicator dye was injected to follow the path of water in the soil. At the end of each irrigation treatment, beds were dissected both length- and crosswise to determine where water had moved. The distance that the dye moved downward both lengthwise and crosswise was measured. Calculations were made to determine percent of the root zone which was wetted. Root zone volume was defined as the width of the bed multiplied by distance between drip emitters multiplied by a rooting depth of 15 inches. Wetted volume was the product of multiplying downward dye movement (15" maximum) by lengthwise movement (with emitter spacing being the maximum) by width of dye movement towards the edges of the bed (36" maximum).

\section{Conclusions}

It can be seen (Table 1) that there is not much difference between the 24 or $27 \mathrm{gal} / 100 \mathrm{ft} /$ hour tapes. It takes both of these tapes 6 hours for the wetting pattern of two adjacent emitters to converge. However, the $32 \mathrm{gal} / 100 \mathrm{ft} /$ hour tape with 4 inch emitter spacing, the wetting patterns converge after only an hour. This tape also allowed for deeper penetration of water and provided less water movement to the sides of the beds than the other two tapes. This is due to the fact that on the commercial farm a very distinguishable compacted layer existed at a depth of 17 inches. No irrigation with any of these tapes was successful in wetting all the way to the shoulders of the bed (Figures 1-6). In further studies at the GCREC-Dover the effect of pulsing irrigation through the drip system will be explored as a means to move water to the edges of the bed obtaining uniform coverage for fertilizer and any other chemical supplied through the irrigation system. 


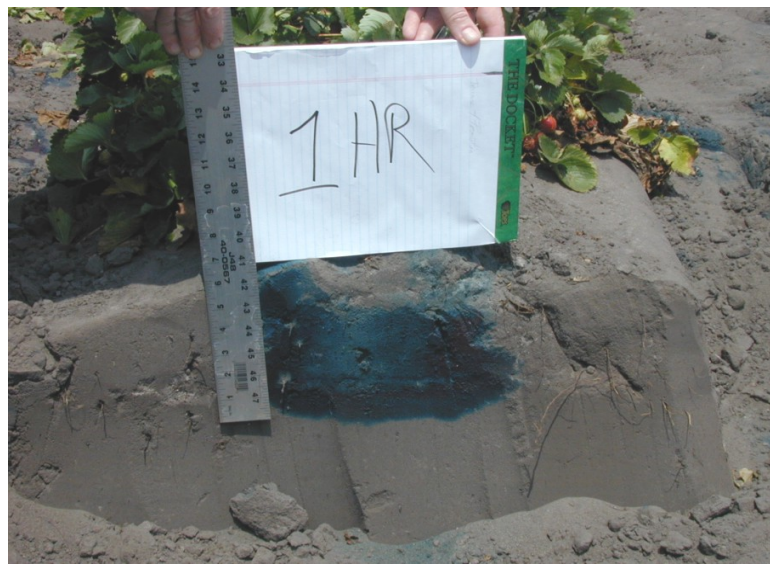

Figure 1. Cross section of beds after 1 hour of irrigation with drip tape that has 4-inch emitter spacing and a flow rate of $32 \mathrm{gal} / 100 \mathrm{ft} / \mathrm{hr}$. Credits: J.R. Duval 2002

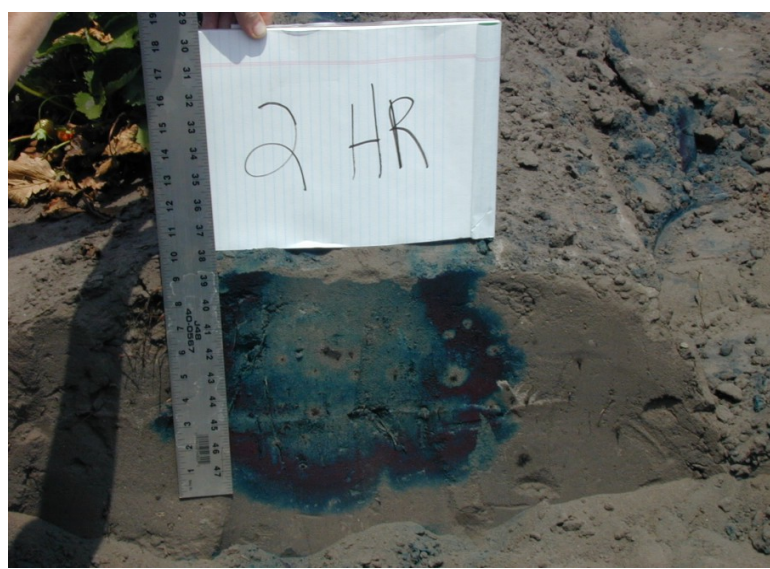

Figure 2. Cross section of beds after 2 hours of irrigation. Credits: J.R. Duval 2002

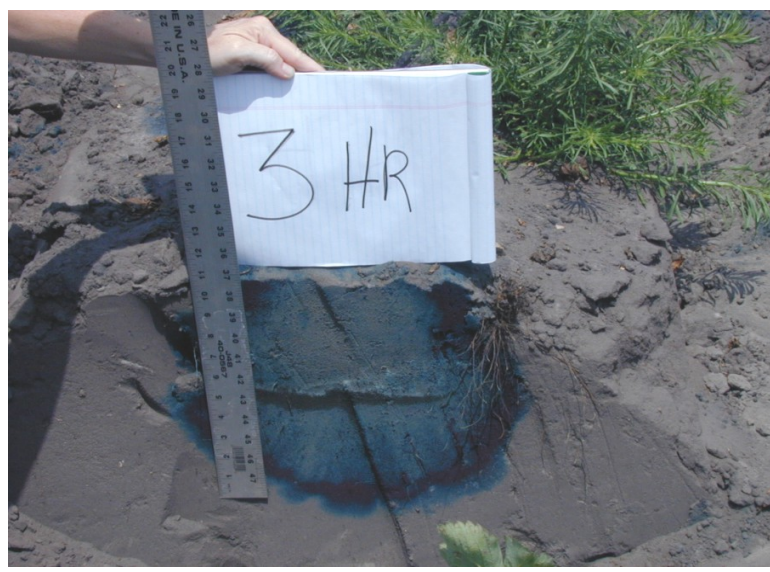

Figure 3. Cross section after 3 hours of irrigation. Credits: J.R. Duval 2002

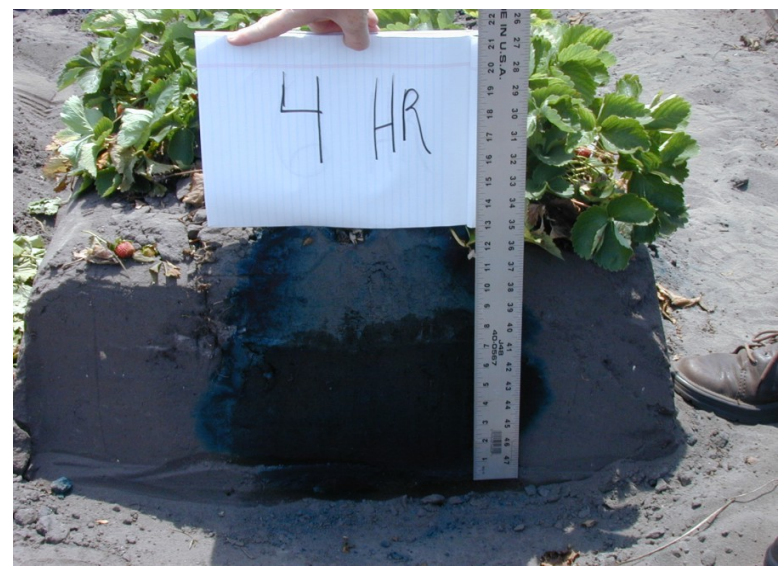

Figure 4. After 4 hours of irrigation. Credits: J.R. Duval 2002

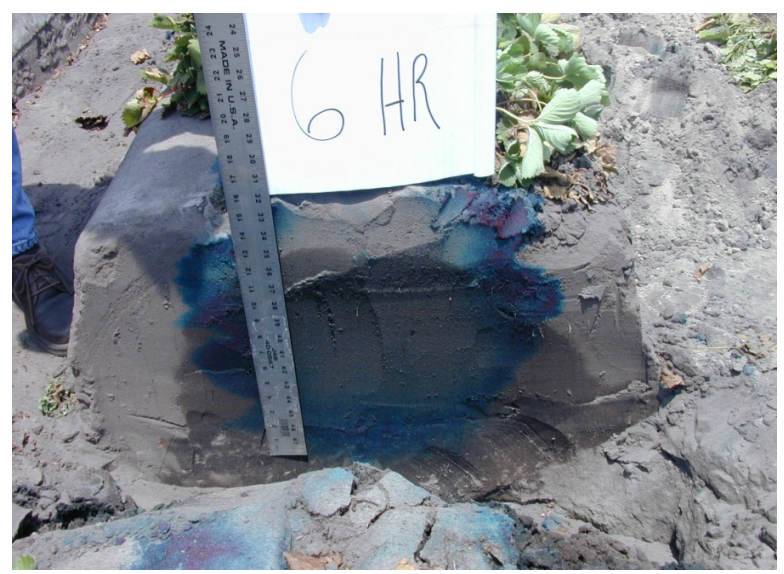

Figure 5. After 6 hours of irrigation Credits: J.R. Duval 2002

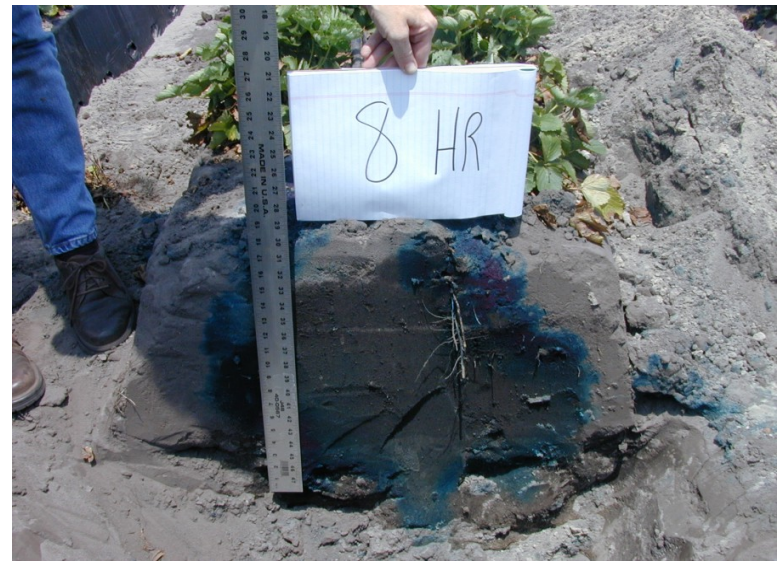

Figure 6. Cross section of beds after 8 hours. Credits: J.R. Duval 2002 
Table 1. Percent of root zone wetted by 3 different drip tapes over 8 hours.

\begin{tabular}{||l|l|l|l|l||}
\hline \hline & Gal/100 ft/hour & 24 & \multicolumn{1}{|c||}{$\mathbf{2 7}$} & 32 \\
\hline & emitter spacing & 12" & 12" & $4 "$ \\
\hline $\begin{array}{l}\text { Hours of } \\
\text { Irrigation }\end{array}$ & & & & \\
\hline $\mathbf{1}$ & & 14 & 16 & 15 \\
\hline $\mathbf{2}$ & & 27 & 32 & 20 \\
\hline $\mathbf{3}$ & & 41 & 39 & 28 \\
\hline $\mathbf{4}$ & & 47 & 38 & 38 \\
\hline $\mathbf{6}$ & & 51 & 53 & 51 \\
\hline $\mathbf{8}$ & & 63 & 61 & 56 \\
\hline \hline
\end{tabular}

